\title{
Long-Term Trends in Near-Surface Wind Speed over the Southern Hemisphere: A Preliminary Analysis
}

\author{
Luiz Felipe N. Cardosoํㅜ, Wanderson Luiz Silva ${ }^{1}$, Maria G. A. Justi da Silva ${ }^{2}$ \\ ${ }^{1}$ Department of Meteorology, Federal University of Rio de Janeiro, Rio de Janeiro, Brazil \\ ${ }^{2}$ Meteorology Laboratory, State University of Northern of Rio de Janeiro, Macaé, Brazil \\ Email: felipenc2@gmail.com, wanderweather@gmail.com, justi.meteoro@gmail.com
}

Received 15 June 2016; accepted 16 July 2016; published 19 July 2016

Copyright (C) 2016 by authors and Scientific Research Publishing Inc.

This work is licensed under the Creative Commons Attribution International License (CC BY). http://creativecommons.org/licenses/by/4.0/

(c) () D Den Access

\begin{abstract}
Many studies that discuss observed trends in wind speed focus primarily on regions of the Northern Hemisphere, so there is little research directed to the Southern Hemisphere. This paper presents a preliminary investigation of possible statistically significant trends in wind speed over the Southern Hemisphere, with a detailing on the South American continent, between 1961 and 2008. Thus, data from the 20th Century Reanalysis V2 were examined with statistical tests of MannKendall and Sen's Bend in order to establish the significance and the magnitude of detected trends. The previous results indicate statistically significant trends of increase in average wind speed over the equatorial region of the planet, as well as in the eastern sector of the South Pacific and South Atlantic Oceans. In South America, the most significant trends of decrease in wind speed were noted in some areas of the southern sector of the continent, even as in the adjacent Atlantic Ocean to Argentina. Further studies should be performed to physically support the occurrence of these trends in wind speed. In addition, other observed and reanalysis data sets should be explored to update and corroborate these primary analyzes.
\end{abstract}

\section{Keywords}

Climate Change, Mann-Kendall, Reanalysis, Southern Hemisphere, Trends, Wind Speed

\section{Introduction}

Most of the effort in variability and climate change studies focuses on variables related to air temperature and precipitation. These two climatic elements are very relevant and have been researched through observed and si- 
mulated data. However, as [1], the practical effects of any climate variations or changes do not involve a single climatic component, but rather the result of a combination of variables. Several impacts of climate variability directly or indirectly involve the wind speed. For instance, one of the main ways in which variations in air temperature affect the biosphere is through the sensible heat flux density, which is dependent on the wind speed.

A significant example of this relationship is the ocean evaporation, that is, the process by which water molecules change from liquid phase to vapor phase in the atmosphere-ocean interface. According to [2], the evaporation depends on three basic requirements: thermal energy, moisture difference between the atmosphere and the ocean, and the wind speed. The air turbulent motion associated with the wind speed and surface roughness facilitates evaporation because it carries water vapor from the evaporated surface and helps to maintain a vertical moisture gradient between the atmosphere and the ocean. Furthermore, the wind speed also has a significant economic and social importance. Since the 20th century, according to [3], with the rapid growth of the world economy, energy demand is multiplying and energy industries are in massive process of wind resources development. Wind power has as main feature its abundant, clean and renewable generation.

Several studies as [4]-[6], among others, present researches associated with wind speed variability and changes during the years. However, much of the work is concentrated in regions of the Northern Hemisphere, so there is little information to the Southern Hemisphere. In this context, this work has the objective of presenting a preliminary analysis of possible statistically significant trends in wind speed on the Southern Hemisphere, with a detailing on South America, between 1961 and 2008. This study aims to contribute positively in generating relevant information for strategic areas of society.

\section{Data and Methodology}

\subsection{Study Area}

The study area of this research specifically carries the Southern Hemisphere (Figure 1). Most of this hemisphere is covered by water, wherein just $30 \%$ is land area and it comprises $10 \%$ of the world's population.

The South American continent is also analyzed in detail in this work. South America is dominated by warmer climate in the north and colder climate in the south, in addition to being bathed by the Atlantic and Pacific Oceans. In the west coast of the continent are the Andes, the longest continental mountain range in the world. In the northwest sector is the Amazon rainforest, a moist broadleaf forest. These physiographic aspects constitute the complex climatic characterization of the continent.

\subsection{Data}

The database used in this study comes from the reanalysis of the Earth System Research Laboratory/National Oceanic and Atmospheric Administration (ESRL/NOAA), entitled 20th Century Reanalysis V2 [7]. The meteorological variables fields are available on a time scale of 6 (six) hours with a horizontal resolution of $2.0^{\circ}$ and $24^{\circ}$ vertical levels.

The data are distributed by NOAA National Model Archive and Distribution System (NOMADS). From the monthly average of the zonal (U) and meridional (V) wind components at 10 meters for the period of January 1961 to December 2008 (48 years), the wind speed at the surface of the Southern Hemisphere was calculated using the GrADS ${ }^{\circledR}$ software. The resulting wind speed data is then verified, without any further preprocessing, using the statistical tests described in Section 2.3.

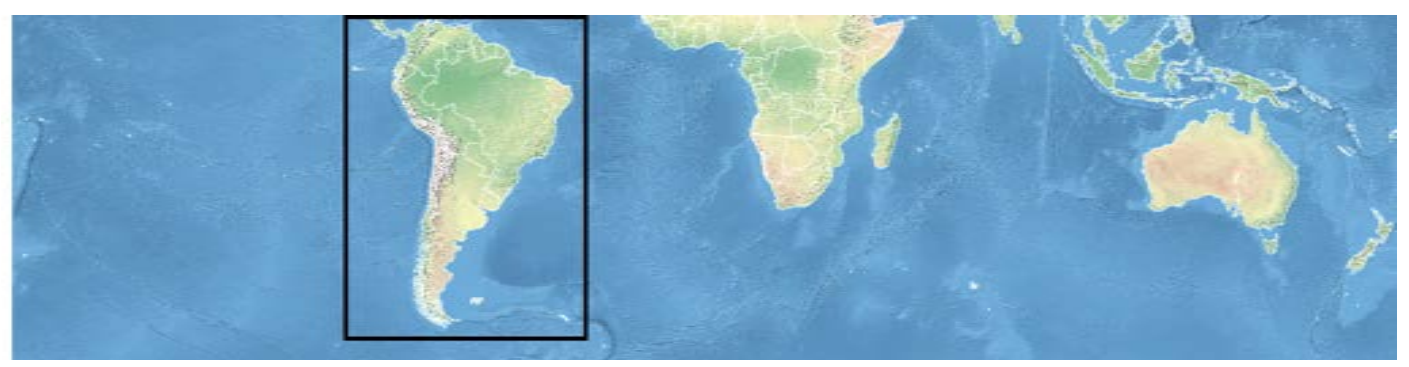

Figure 1. Study area of this research, the Southern Hemisphere. The black box delimits the focused area of the South American continent, also analyzed in this paper. 


\subsection{Statistical Tests}

To analyze the significance of the observed trends in wind speed is used the Mann-Kendall non-parametric statistical test [8]. This test considers that, in the hypothesis of time series stability, the succession of values occurs independently and the probability distribution must always remain the same (simple random series). The Mann-Kendall test is the most appropriate method to analyze the significance of possible climate changes in historical series [9].

One of the benefits of this test is the fact that it is a non-parametric test, that is, the data do not need belong to a particular distribution. Another advantage is that the result is less affected by outliers, because its calculation is based on the sign of the differences and not directly in the variable values. The formulas used for calculating Mann-Kendall statistical test are:

$$
Z=\frac{S+u}{[\operatorname{VAR}(S)]^{\frac{1}{2}}}
$$

where: $u=-1$ if $S>0$; $u=0$ if $S=0$; and $u=+1$ if $S<0$;

$$
S=\sum_{k=1}^{n-1} \sum_{j=k+1}^{n} \operatorname{sign}\left(x_{j}-x_{k}\right)
$$

where:

$$
\operatorname{sign}\left(x_{j}-x_{k}\right)=1 \text { if } x_{j}-x_{k}>0 ; \operatorname{sign}\left(x_{j}-x_{k}\right)=0 \text { if } x_{j}-x_{k}=0 \text {; } \operatorname{sign}\left(x_{j}-x_{k}\right)=-1 \text { if } x_{j}-x_{k}<0
$$

and:

$$
\operatorname{VAR}(S)=\frac{1}{18}\left[n(n-1)(2 n+5)-\sum_{p=1}^{g} t_{p}\left(t_{p}-1\right)\left(2 t_{p}+5\right)\right]
$$

In Equation (2), $x$ are the time series, ranging from $k(j=k+1)$ to $n$. The number of groups of repeated values in each group $p$ (to $g$ ) is represented by $t$ in Equation (4). The trend is indicated by the Z-value in Equation (1), where a positive (negative) $Z$ means an increasing (a decreasing) trend by Normal table. If the probability $p$ (p-value) of the Mann-Kendall test is equal to or less than the significance level $\alpha$, a statistically significant trend exists, whereas a $p$-value greater than $\alpha$ confirms a non-significant trend. The adopted significance level $\alpha$ for this work is $0.05 \%$ or $5 \%$, that is, a confidence level $\beta$ of $0.95 \%$ or $95 \%$.

Sen's Bend is a non-parametric method (assuming a linear trend) used to estimate the magnitude of trends [10]. To calculate the Sen's Bend, all the curvatures from all pairs of values are computed using time series:

$$
\text { SEN }=\text { median }\left(\frac{x_{j}-x_{i}}{j-i}\right), \forall j>i
$$

As Sen's Bend is also sensitive to outliers and missing data, this test is more rigorous than the usual regression curve and provides a more realistic measure of trends in time series. Statistical tests of this research were conducted using the MatLab ${ }^{\circledR}$ software.

\section{Preliminary Results and Discussion}

To assess the results, Figure 2 was created. It shows the identified trends in the mean wind speed over the Southern Hemisphere between January 1961 and December 2008 (m/s per month); the areas with an upward trend in wind speed are marked with colors ranging from yellow to red, while areas with decreasing trend are represented by colors ranging from light blue to dark blue; regions with no statistically significant trend is symbolized by the white color.

It was noted a statistically significant increase of the wind speed at 95\% confidence level in the tropical portion as a whole, but with greater magnitude in the equatorial region (on the threshold between the Northern and Southern Hemispheres). These changes that reach over $+3.6 \times 10^{-3} \mathrm{~m} / \mathrm{s}$ per month are possibly associated with an intensification of the confluence area of the trade winds and, consequently, changes in the region of the equatorial trough related to the Intertropical Convergence Zone (ITCZ). 


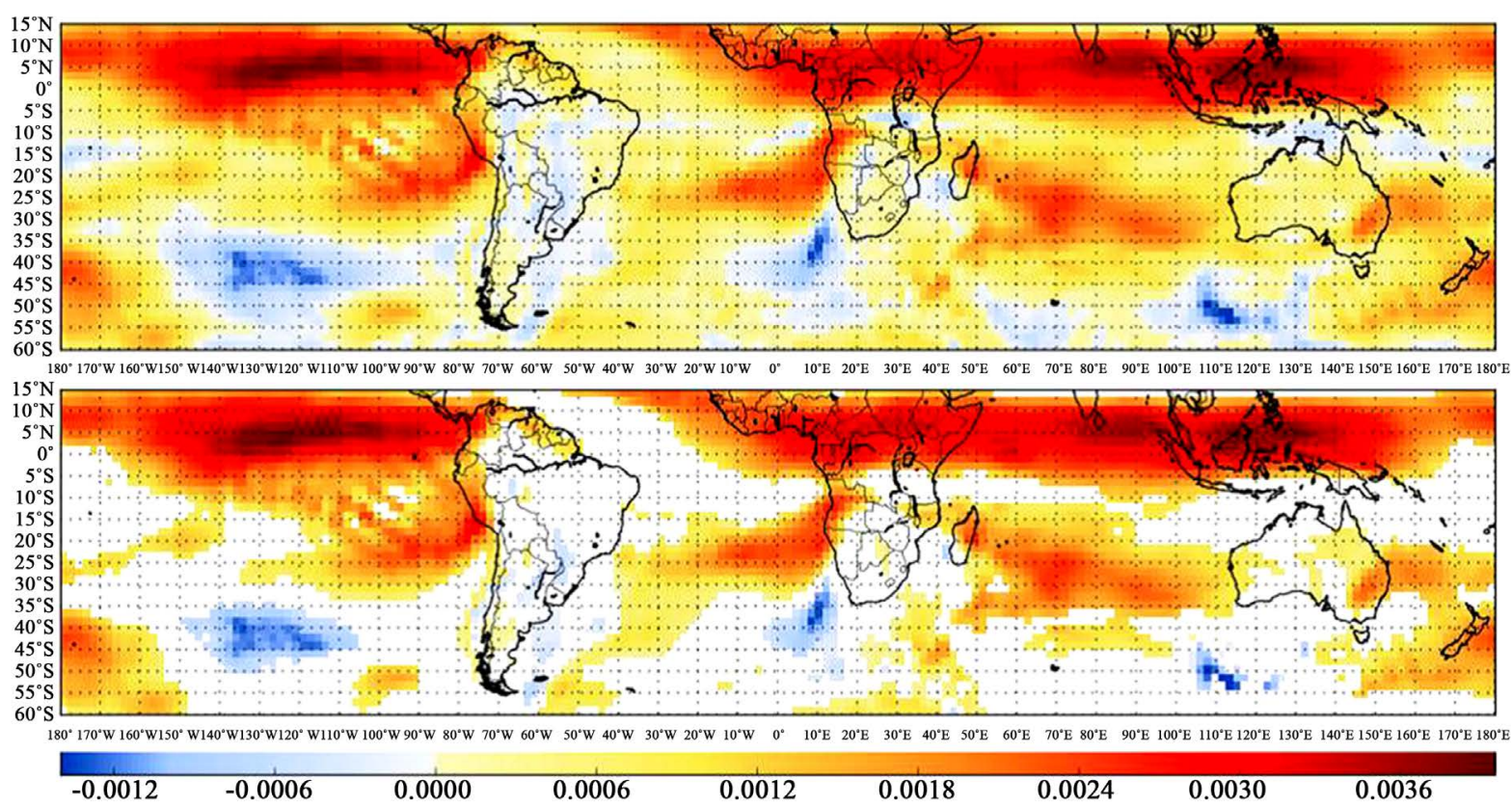

Figure 2. Observed trends in wind speed for the Southern Hemisphere (above) between January 1961 and December 2008 $(\mathrm{m} / \mathrm{s}$ per month). The figure below only shows the regions where the trends were statistically significant at $95 \%$ confidence level.

In much of the tropical and subtropical oceanic portion of the Southern Hemisphere (between $10^{\circ} \mathrm{S}$ and $30^{\circ} \mathrm{S}$ ), including the Pacific, Atlantic and Indian Oceans, is also noted a marked upward trend of average wind speed around $+3.0 \times 10^{-3} \mathrm{~m} / \mathrm{s}$ per month that is likely aggregated to changes in the circulation of eastern outskirts of the subtropical anticyclones located in these regions. Some significant trends of decrease in the wind speed around $-1.2 \times 10^{-3} \mathrm{~m} / \mathrm{s}$ per month were found in isolated areas of the oceanic mid-latitudes of the Southern Hemisphere, that is, in frontogenetic regions of emphatic meridional thermal gradient, especially on the South Pacific Ocean. These alterations may be attached to changes in this north-south temperature gradient due to the observed warming in all regions of the world during the 20th century [11].

On the South American continent and adjacent oceans (Figure 3), there is a statistically significant increase in the mean wind speed in the northeast Pacific Ocean, as already noted and commented in Figure 2. A wind speed increase is also identified on the southwestern Atlantic Ocean (about $+1.0 \times 10^{-3} \mathrm{~m} / \mathrm{s}$ per month), but with lower magnitude to the Pacific Ocean. This alteration, which extends to the coast of southeastern Brazil, can be examined in relation to the frequency trend of frontal systems in southeastern South America and near Atlantic Ocean over the past years.

It is also observed that the average wind speed is decreasing significantly at a rate higher than $-0.5 \times 10^{-3} \mathrm{~m} / \mathrm{s}$ per month over the Atlantic Ocean adjacent to Argentina, as well as some sectors at the north of this country, at Paraguay, in the west of the South of Brazil and Mato Grosso do Sul State (Brazil). Through investigations into the precipitation over the past decades, it is possible to emphasize that these are regions where a statistically significant growth trend of annual rainfall has been observed [11].

[12] showed a significant increase at 99\% confidence level of the turbulent heat flux (latent and sensible heat) on the east coast of Argentina. These changes may be related to the significant reduction in average wind speed in this area.

\section{Conclusions and Future Work}

This study presents a preliminary assessment of possible statistically significant trends in wind speed over the Southern Hemisphere, with a detailing on the South American continent, during the second half of the 20th century. This research aims to collaborate in the production of key information for strategic sectors of society. Thus, reanalysis data were analyzed with posterior use of statistical tests to determine the significance and magnitude of the detected trends. 

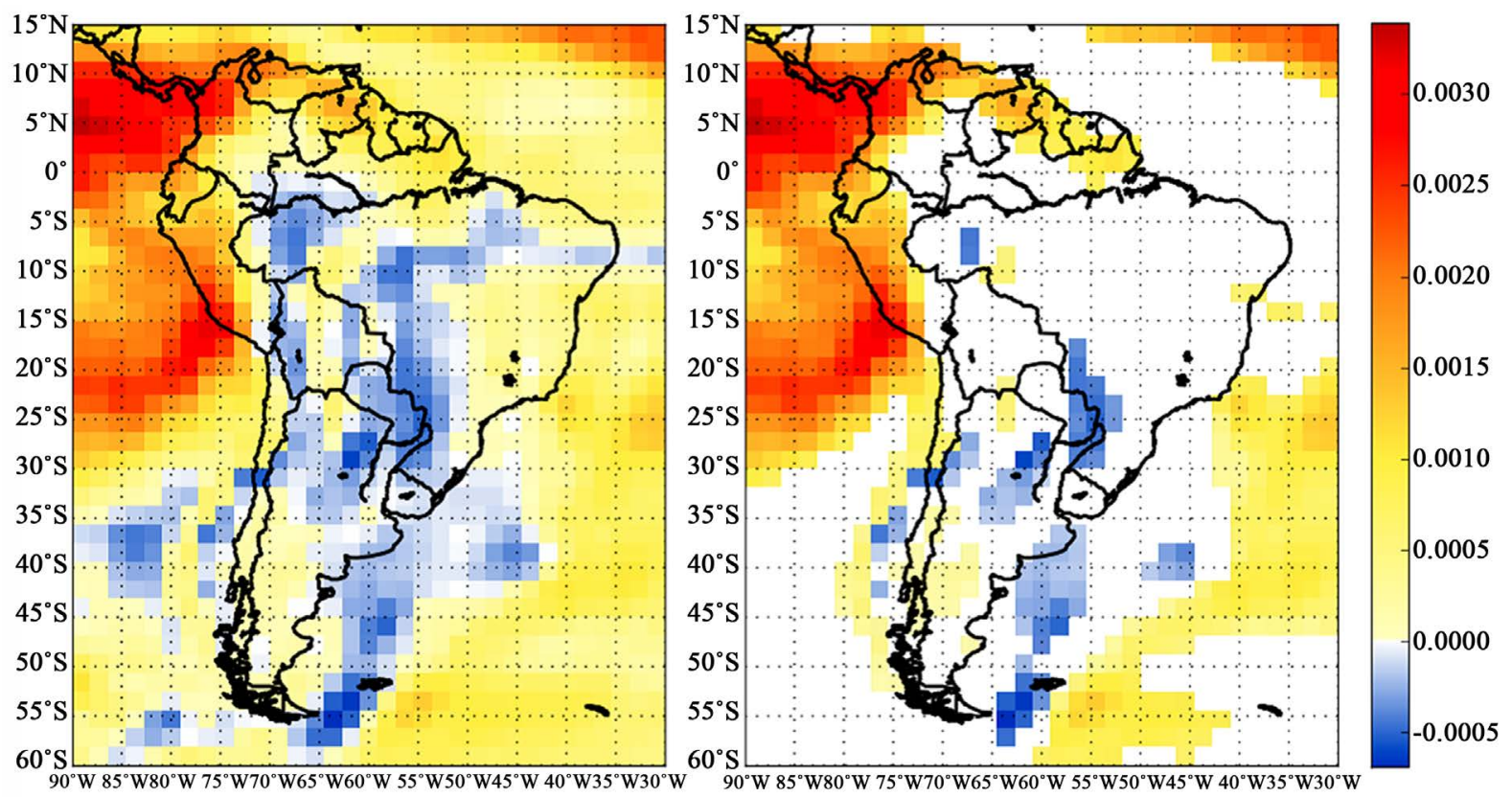

Figure 3. Same as Figure 2 for the South American continent. The figure on the right only shows the regions where the trends were statistically significant at $95 \%$ confidence level.

Statistically significant trends have shown an increase in the average wind speed over the equatorial region of the planet, as well as in the eastern sector of the South Pacific and South Atlantic. Most of the Indian Ocean is also experiencing an increase in wind speed in the last decades. In South America, the most significant trends of reduction in the average wind speed are confined to some areas of southern portion of the continent and to the Atlantic Ocean portion adjacent to Argentina.

Future work should be undertaken to investigate the reasons associated with such detected trends in wind speed. Therefore, trends related to other climate variables such as precipitation and air temperature could help understanding the wind speed trends. In addition, new observed and reanalysis data sets, such as the Climate Forecast System Reanalysis (CFSR), whose coupled ocean model tends to improve the reliability of the statistical results, should be used to update and confirm these preliminary analyzes.

\section{References}

[1] Tuller, S.E. (2004) Measured Wind Speed Trends on the West Coast of Canada. International Journal of Climatology, 24, 1359-1374. http://dx.doi.org/10.1002/joc.1073

[2] Yu, L. (2007) Global Variations in Oceanic Evaporation (1958-2005): The Role of the Changing Wind Speed. Journal of Climate, 20, 5376-5390. http://dx.doi.org/10.1175/2007JCLI1714.1

[3] Jiang, Y., Luo, Y., Zhao, Z. and Tao, S. (2010) Changes in Wind Speed over China during 1956-2004. Theoretical and Applied Climatology, 99, 421-430. http://dx.doi.org/10.1007/s00704-009-0152-7

[4] Keimig, F.T. and Bradley, R.S. (2002) Recent Changes in Wind Chill Temperatures at High Latitudes in North America. Geophysical Research Letters, 29, 1-4. http://dx.doi.org/10.1029/2001gl013228

[5] Pirazzoli, P.A. and Tomasin, A. (2003) Recent Near-Surface Wind Changes in the Central Mediterranean and Adriatic Areas. International Journal of Climatology, 23, 963-973. http://dx.doi.org/10.1002/joc.925

[6] Pryor, S.C. and Barthelmie, R.J. (2003) Long-Term Trends in Near-Surface Flow over the Baltic. International Journal of Climatology, 23, 271-289. http://dx.doi.org/10.1002/joc.878

[7] Compo, G.P., et al. (2011) The Twentieth Century Reanalysis Project. Quarterly Journal of the Royal Meteorological Society, 137, 1-28. http://dx.doi.org/10.1002/qj.776

[8] Sneyers, R. (1975) Sur L’analyse Statistique des Series D’óbservations. Organisation Méteorologique Mondial, 192 p.

[9] Goossens, C. and Berger, A. (1986) Annual and Seasonal Climatic Variations over the Northern Hemisphere and Europe during the Last Century. Annales Geophysicae, 4, 385-400. 
[10] Sen, P.K. (1968) Estimates of the Regression Coefficient Based on Kendall's Tau. Journal of the American Statistical Association, 63, 1379-1389. http://dx.doi.org/10.1080/01621459.1968.10480934

[11] Intergovernmental Panel on Climate Change-IPCC (2013) Climate Change 2013: Fifth Assessment Report of the Intergovernmental Panel on Climate Change. In: Stocker, T.F., Qin, D., Plattner, G.K., Tignor, M., Allen, S.K., Boschung, J., Nauels, A., Xia, Y., Bex, V. and Midgley, P.M., Eds., Cambridge University Press, Cambridge, 1535 p.

[12] Herman, A. (2015) Trends and Variability of the Atmosphere-Ocean Turbulent Heat Flux in the Extratropical Southern Hemisphere. Scientific Reports, 14900. http://dx.doi.org/10.1038/srep14900

\section{Submit or recommend next manuscript to SCIRP and we will provide best service for you:}

Accepting pre-submission inquiries through Email, Facebook, Linkedin, Twitter, etc A wide selection of journals (inclusive of 9 subjects, more than 200 journals)

Providing a 24-hour high-quality service

User-friendly online submission system

Fair and swift peer-review system

Efficient typesetting and proofreading procedure

Display of the result of downloads and visits, as well as the number of cited articles

Maximum dissemination of your research work

Submit your manuscript at: http://papersubmission.scirp.org/ 